\title{
Selective serotonin reuptake inhibitors (SSRIs) prevent meta-iodobenzylguanidine (MIBG) uptake in platelets without affecting neuroblastoma tumor uptake
}

Thomas Blom ${ }^{1,2}$, Rutger Meinsma², Marja Rutgers ${ }^{3}$, Corine Buitenhuis ${ }^{3}$, Marieke Dekken-Van den Burg ${ }^{4}$, André B. P. van Kuilenburg ${ }^{2+}$ and Godelieve A. M. Tytgat ${ }^{1 *+}$ (D)

\begin{abstract}
Background: The therapeutic use of $\left[^{131} 1\right]$ meta-iodobenzylguanidine $\left(\left[^{[31} \mid\right] \mathrm{MIBG}\right)$ is often accompanied by hematological toxicity, mainly consisting of persistent and severe thrombocytopenia. While MIBG accumulates in neuroblastoma cells via selective uptake by the norepinephrine transporter (NET), the serotonin transporter (SERT) is responsible for cellular uptake of MIBG in platelets. In this study, we have investigated whether pharmacological intervention with selective serotonin reuptake inhibitors (SSRIs) may prevent radiotoxic MIBG uptake in platelets without affecting neuroblastoma tumor uptake.

Methods: To determine the transport kinetics of SERT for [ ${ }^{125}$ I]MIBG, HEK293 cells were transfected with SERT and uptake assays were conducted. Next, a panel of seven SSRIs was tested in vitro for their inhibitory potency on the uptake of $\left[{ }^{125} \mathrm{l}\right] \mathrm{MIBG}$ in isolated human platelets and in cultured neuroblastoma cells. We investigated in vivo the efficacy of the four best performing SSRIs on the accumulation of [ $\left.{ }^{125} \mathrm{I}\right] \mathrm{MIBG}$ in nude mice bearing subcutaneous neuroblastoma xenografts. In ex vivo experiments, the diluted plasma of mice treated with SSRIs was added to isolated human platelets to assess the effect on [ ${ }^{125}$ I]MIBG uptake.

Results: SERT performed as a low-affinity transporter of [ ${ }^{125}$ I]MIBG in comparison with NET $\left(K_{\mathrm{m}}=9.7 \mu \mathrm{M}\right.$ and $0.49 \mu \mathrm{M}$, respectively). Paroxetine was the most potent uptake inhibitor of both serotonin $\left(\mathrm{IC}_{50}=0.6 \mathrm{nM}\right)$ and $\mathrm{MIBG}$ $\left(\mathrm{IC}_{50}=0.2 \mathrm{nM}\right)$ in platelets. Citalopram was the most selective SERT inhibitor of [ $\left.{ }^{125} \mathrm{I}\right] \mathrm{MIBG}$ uptake, with high SERT affinity in platelets $\left(I C_{50}=7.8 \mathrm{nM}\right)$ and low NET affinity in neuroblastoma cells $\left(I C_{50}=11.940 \mathrm{nM}\right)$. The in vivo tested SSRIs (citalopram, fluvoxamine, sertraline, and paroxetine) had no effect on [ $\left.\left.{ }^{125}\right]\right] \mathrm{MIBG}$ uptake levels in neuroblastoma xenografts. In contrast, treatment with desipramine, a NET selective inhibitor, resulted in profoundly decreased xenograft [ ${ }^{125}$ ] MIBG levels $(p<0.0001$ ). In ex vivo [25I]MIBG uptake experiments, 100- and 34-fold diluted murine plasma of mice treated with citalopram added to isolated human platelets led to a decrease in MIBG uptake of $54-76 \%$, respectively.

(Continued on next page)
\end{abstract}

\footnotetext{
* Correspondence: g.a.m.tytgat@prinsesmaximacentrum.nl

${ }^{+}$André B. P. van Kuilenburg and Godelieve A. M. Tytgat contributed equally to this work.

${ }^{1}$ Princess Máxima Center for Pediatric Oncology, Utrecht, The Netherlands Full list of author information is available at the end of the article
}

\section{Springer Open}

(c) The Author(s). 2020 Open Access This article is licensed under a Creative Commons Attribution 4.0 International License, which permits use, sharing, adaptation, distribution and reproduction in any medium or format, as long as you give appropriate credit to the original author(s) and the source, provide a link to the Creative Commons licence, and indicate if changes were made. The images or other third party material in this article are included in the article's Creative Commons licence, unless indicated otherwise in a credit line to the material. If material is not included in the article's Creative Commons licence and your intended use is not permitted by statutory regulation or exceeds the permitted use, you will need to obtain permission directly from the copyright holder. To view a copy of this licence, visit http://creativecommons.org/licenses/by/4.0/. 
(Continued from previous page)

Conclusion: Our study demonstrates for the first time that SSRIs selectively inhibit MIBG uptake in platelets without affecting MIBG accumulation in an in vivo neuroblastoma model. The concomitant application of citalopram during $\left[{ }^{131}\right.$ I]MIBG therapy seems a promising strategy to prevent thrombocytopenia in neuroblastoma patients.

Keywords: Meta-iodobenzylguanidine (MIBG), Hematological toxicity, Thrombocytopenia, Platelets, Selective serotonin reuptake inhibitor (SSRI)

\section{Background}

Neuroblastoma, originating from the early developing embryonic sympathetic nervous system, is the most common extracranial solid tumor of childhood [1]. Despite intensive multimodality treatment, the overall survival rate for high-risk neuroblastoma patients remains poor [2]. Approximately $90 \%$ of neuroblastomas express the norepinephrine transporter (NET) [3], enabling the application of meta-iodobenzylguanidine (MIBG), a structural analog of norepinephrine, for imaging and treatment purposes (Fig. 1). Whereas the iodine-123 radiolabeled form is used as a highly selective radioactive imaging agent [5], radioactive iodine-131 MIBG is being used since 1984 in patients with relapsed or refractory neuroblastoma to achieve a tumor response [6]. This treatment in these patients has been accompanied by hematological toxicity, mainly consisting of persistent and severe thrombocytopenia [7-9].

Numerous studies have shown a clear association between the whole-body radiation dose from $\left[{ }^{131} \mathrm{I}\right] \mathrm{MIBG}$ treatment and the severity of hematological toxicity [810]. However, in a recent study consisting of 213 highrisk neuroblastoma patients treated at a single institution, no such relation was observed [11]. Furthermore, thrombocytopenia after $\left[{ }^{125} \mathrm{I}\right] \mathrm{MIBG}$ treatment, a radiopharmaceutical with negligible radiation exposure to nontargeted neighboring cells [12], was unforeseen and far more severe than expected from calculated wholebody radiation doses in neuroblastoma patients [13, 14]. It appears that it is not the iodine-125 in itself that leads to hematological toxicity but the combination of the radioiodine with MIBG, since in patients with advanced colon cancer, high doses of iodine-125-labeled monoclonal antibody did not cause bone marrow toxicity, while the iodine131-labeled antibody caused severe hematological toxicity in $26 \%$ of patients $[15,16]$.

It is conceivable that radiation exposure after selective uptake of MIBG by platelet precursor cells, the bone marrow megakaryocytes, is the major cause of MIBG treatment-associated thrombocytopenia. Human platelets possess the serotonin transporter (SERT, see also Fig. 1) [17], and $\left[{ }^{131} \mathrm{I}\right] \mathrm{MIBG}$ accumulates in human platelets as effectively as the natural substrate serotonin [18]. The aim of this study was to investigate whether prevention of radiolabeled MIBG accumulation in platelets is feasible in vivo, without reducing tumor uptake in nude mice bearing neuroblastoma xenografts.

\section{Methods}

Overexpression of human SERT and NET in HEK293 cells

NET (addgene plasmid \#15475) and SERT (addgene plasmid \#15483) were transiently expressed in HEK293 cells (ATCC ${ }^{\oplus}$ CRL-3216 $^{\text {Tm}}$, Manassas, USA) using XtremeGENE ${ }^{\mathrm{Tm}}$ HP DNA Transfection Reagent (Sigma-Aldrich, St. Louis, USA). To investigate the expression of NET and SERT in the transfected cells, SDS/PAGE was performed on $4-12 \%$ polyacrylamide gel (Lonza, Basel, Switzerland) followed by Western blotting on $0.45 \mu \mathrm{m}$ nitrocellulose (Amersham, Buckinghamshire, UK). Antibody incubation was performed for $1 \mathrm{~h}$ with primary antibodies against NET (NET 17-1) and SERT (ST51-1; both from MAb Technologies, Stone Mountain, USA) and with IRDye ${ }^{\circ} 800 \mathrm{CW}$ Donkey anti-Mouse IgG (Li-cor) as secondary antibody. The Odyssey Imaging System (Li-cor, Lincoln, USA) was used for immunoblot imaging.

\section{Platelet isolation}

Blood was obtained from patients with polycythemia vera or secondary polycythemia. All volunteers gave their informed consent. Platelet-rich plasma (PRP) was prepared as described previously [18]. Results of uptake and inhibition studies were compared to results obtained with PRP prepared from the blood of healthy volunteers as control.

\section{$\left[{ }^{3} \mathrm{H}\right]$ serotonin and $\left[{ }^{125} \mathrm{I}\right] \mathrm{MIBG}$ uptake experiments}

Uptake studies of $\left[{ }^{3} \mathrm{H}\right]$ serotonin and $\left[{ }^{125} \mathrm{I}\right] \mathrm{MIBG}$ in transfected HEK293 cells were performed on cells cultured in 6 wells $\left(9.5 \mathrm{~cm}^{2}\right.$ each) plates. Two days after plating, at a confluence of $80-90 \%$, the culture medium was removed and fresh medium containing MIBG (range $0.05-20 \mu \mathrm{M}$ ) or serotonin (range $0.5-50 \mu \mathrm{M}$ ) was added with a fixed concentration of radioactivity of $3.7 \mathrm{kBq} / \mathrm{ml}$. Cells were co-incubated with monoamine transporter inhibitors at final concentrations ranging from $10^{-10}-10^{-4}$ M. Nonspecific uptake was determined in HEK293 cells transfected with an empty vector alone. After $1 \mathrm{~h}$ of incubation at $37^{\circ} \mathrm{C}$, the cells were washed twice with Hank's Balanced Salt Solution (HBSS), after which the cell-associated radioactivity was extracted with $0.2 \mathrm{M}$ 


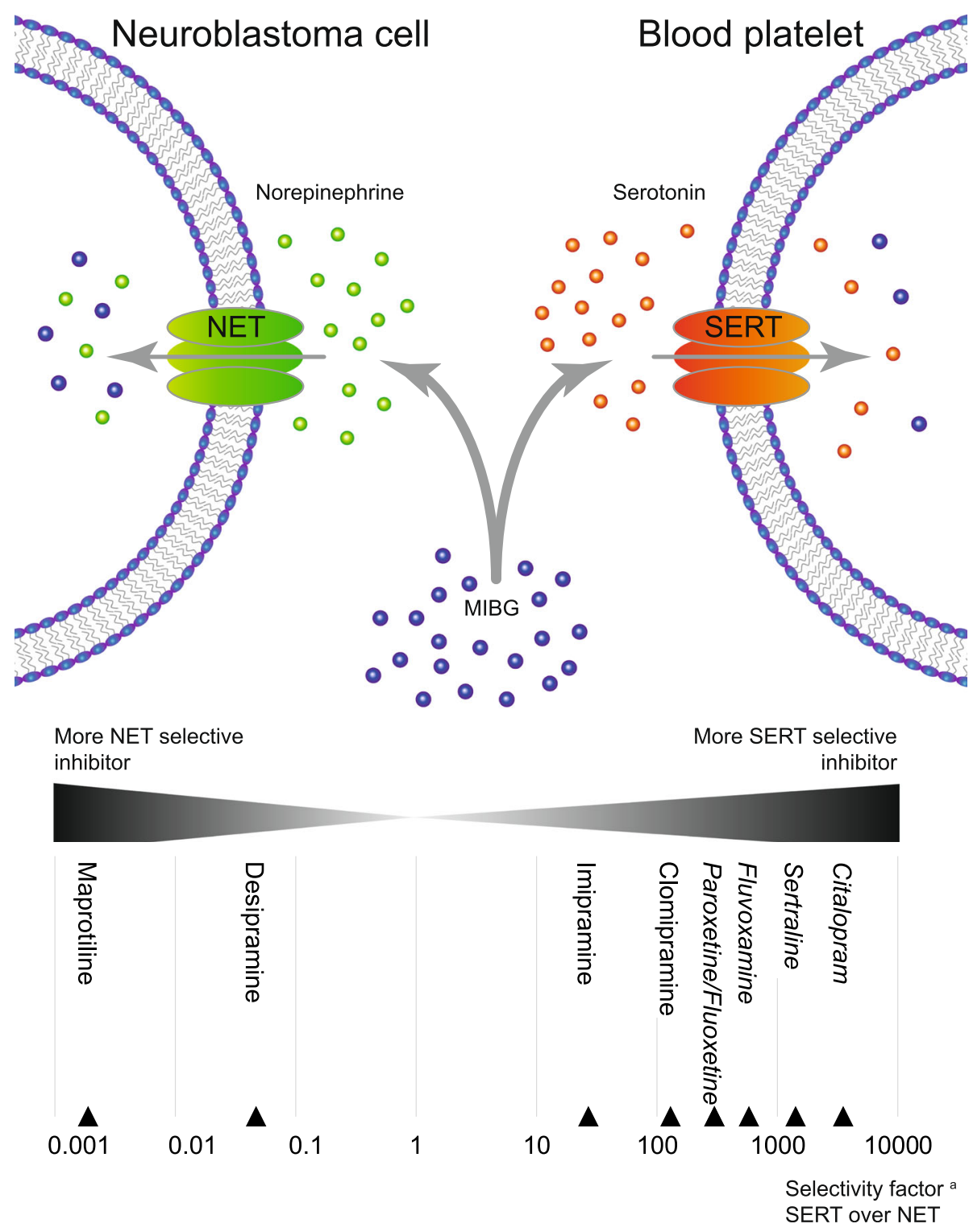

Fig. 1 Uptake of MIBG by NET in neuroblastoma cells and SERT in platelets. Norepinephrine (in green) is the natural substrate of the norepinephrine transporter (NET), serotonin (in red) of the serotonin transporter (SERT). Both monoamine transporters are capable of intracellular transport of MIBG (in blue). ${ }^{a}$ For all monoamine transporter inhibitors, the selectivity factor was calculated from the ratio of the dissociation constants $\left(K_{D}\right)$ for serotonin at SERT and norepinephrine at NET [4]. Selective serotonin reuptake inhibitors (SSRIs) are depicted in italics

sodium hydroxide and counted in Ultima Gold ${ }^{\bullet}$ (PerkinElmer, Waltham, USA) scintillation fluid with a PerkinElmer Tri-Carb liquid scintillation counter (4910TR).

Uptake studies of $\left[{ }^{3} \mathrm{H}\right]$ serotonin and $\left[{ }^{125} \mathrm{I}\right] \mathrm{MIBG}$ in platelets were performed as previously described [18]. Vials of $0.5 \mathrm{ml}$ PRP contained on average $0.97 \pm 0.12 \times$ $10^{8}$ platelets (mean $\pm \mathrm{SD}, n=17$ ) to which $3.7 \mathrm{kBq} / \mathrm{ml}$ of radiolabeled serotonin or MIBG was added, supplemented with cold MIBG to a final concentration of $10^{-8}$ $M$. The different monoamine transporter inhibitors were added at final concentrations ranging from $10^{-12}$ to $10^{-4} \mathrm{M}$. Platelets were incubated at $37^{\circ} \mathrm{C}$ for $15 \mathrm{~min}$ (serotonin) or $4 \mathrm{~h}$ (MIBG), after which the platelets were spun down and washed and radioactivity was counted as described above.

The human neuroblastoma cell line SK-N-SH (ATCC HTB $\left.11^{\mathrm{xm}}\right)$ and the rat pheochromocytoma cell line PC12 $\left(\right.$ ATCC $^{\otimes}$ CRL-1721 $^{\mathrm{sN}}$ ), both expressing NET [19], were routinely cultured in 6-well culture plates [20]. The highly differentiated neuroadrenergic PC12 cells were included to investigate the role of cytoplasmic storage granules. $\left[{ }^{125} \mathrm{I}\right]$ MIBG uptake and inhibition experiments were performed in PC12 cells, which are rich in storage granules and do, in this respect, resemble platelets, and 
in SK-N-SH cells, which contain few storage granules [20]. All experiments were conducted as previously described [18].

Total uptake was calculated as a percentage of the added radioactivity and expressed relatively to the uptake of cells without inhibitor. Nonspecific uptake of substrate was determined by co-incubating cells with excess imipramine (30 or $4 \mu \mathrm{M}$ imipramine for platelets and neuroblastoma, respectively) [18].

Effect of the monoamine transporter uptake inhibitors on the $\left[{ }^{125}\right.$ I]MIBG tumor uptake in vivo

Female athymic BALB/c nu/nu mice were bred in the animal facility of the Netherlands Cancer Institute. Experiments were performed in accordance with the national regulations for animal experimentations and approved by the local animal welfare committee. Subcutaneous (s.c.) neuroblastoma tumors consisted of either first passages of intrasplenic-induced SK-N-SH xenografts or later passages from s.c. propagation of the xenograft [19]. The model of SK-N-SH neuroblastoma-xenografted mice has been shown to be clinically relevant due to its selective MIBG tumor retention and sensitivity to therapeutic $\left[{ }^{131} \mathrm{I}\right]$ MIBG dosages $[19,21]$. The tumor volume doubling time was on average 5 days. The toxicity of each monoamine transporter inhibitor was assessed in 2 to 5 non-tumor-bearing nude mice by $1 \mathrm{~h}$ careful observation following intraperitoneal (IP) injection of the monoamine transporter inhibitor. Applied inhibitor doses were based on earlier studies (summarized in Electronic Supplementary Material: Table I) and varied from 2 to $50 \mathrm{mg} / \mathrm{kg}$. Provided that no toxicity was observed, plasma of these animals was subsequently analyzed in the ex vivo bioassay described below. The effect of the monoamine transporter inhibitors on the MIBG biodistribution was studied in xenografted mice of 10-14 weeks old (mean body weight $24.0 \mathrm{~g}$ ), and the average tumor size was to $0.23 \mathrm{~g}$ (range $0.14-0.30 \mathrm{~g}$ ). First, mice were treated IP with either a monoamine transporter inhibitor or sodium chloride (control). Thirty minutes later, they received an injection in the tail vein with $1 \mu \mathrm{g}$ MIBG spiked with $4.0-8.0 \mathrm{kBq}$ $\left[{ }^{125} \mathrm{I}\right] \mathrm{MIBG}$. One hour after administration of the radiopharmaceutical, the animals were bled from the carotid artery under ether anesthesia and dissected. Tumors and tissues of interest were blotted to remove adhering blood, weighted, and gamma counted. The $\left[{ }^{125}\right.$ I]MIBG tissue levels were expressed as the percentage of the injected radioactivity dose per gram tissue. Mice bearing PC12 pheochromocytoma xenografts induced by direct s.c. injections of PC12 cells were used in similar uptake and inhibition experiments.

\section{Ex vivo bioassay of murine plasma SSRI activity}

The biological activity of the SSRI in the circulation of the nude mice was analyzed using a bioassay similar to that described for humans [22, 23] which determines the inhibitory potency of the murine plasma (containing the SSRI) on the $\left[{ }^{125}\right.$ I]MIBG uptake in human platelets. One hour after the SSRI administration, mice blood was centrifuged to obtain the plasma, which was stored at $20^{\circ} \mathrm{C}$ until analysis. For each SSRI, plasma of 2 to 5 animals was pooled. In the bioassay, we mixed $500 \mu \mathrm{l} \mathrm{hu-}$ man PRP with $5 \mu \mathrm{l}$ or $15 \mu \mathrm{l}$ murine plasma to obtain 34to 100 -fold dilutions of the murine plasmas. Pooled plasma from 6 untreated mice served as control plasma. The inhibition of uptake of $\left[{ }^{125} \mathrm{I}\right]$ MIBG by human platelets was determined as described above.

\section{(Radio) chemicals}

All SSRIs (alaproclate- $\mathrm{HCl}$, citalopram- $\mathrm{HBr}$, fluvoxamine-maleate, fluoxetine- $\mathrm{HCl}$, norfluoxetine- $\mathrm{HCl}$, paroxetine- $\mathrm{HCl}$, sertraline- $\mathrm{HCl}$ ) and other monoamine transporter inhibitors (imipramine- $\mathrm{HCl}$, desipramine$\mathrm{HCl}$, clomipramine- $\mathrm{HCl}$, maprotiline- $\mathrm{HCl}$ ) were obtained from Sigma-Aldrich (St. Louis, USA). $\left[{ }^{125} \mathrm{I}\right] \mathrm{MIBG}$ (specific activity $\approx 0.65 \mathrm{TBq} / \mathrm{mmol}$ ) was purchased from Chelatec (Saint-Herblain, France). $\left[{ }^{3} \mathrm{H}\right]$ Serotonin (5-hydroxytryptamine creatinine sulfate, specific activity $\approx$ 3.84. TBq/mmol) was purchased from PerkinElmer.

\section{Data analysis}

Unless stated otherwise, results are expressed as mean \pm SD (n). Results were statistically analyzed using the Student $t$ test and were considered significant if $p<0.05$. Kinetic transport parameters $\left(K_{\mathrm{m}}\right.$ and $\left.V_{\max }\right)$ and half maximal inhibitory concentration values $\left(\mathrm{IC}_{50}\right)$ were calculated using nonlinear regression analysis in GraphPad Prism software (version 8; San Diego, USA). GraphPad Prism software was used to create all figures.

\section{Results \\ Uptake and inhibition in SERT- and NET-transfected HEK293 cells}

To determine the affinity of SERT for MIBG and its natural substrate serotonin, HEK293 cells were transfected with cDNA coding for SERT (HEK-SERT). In addition, HEK293 cells were transfected with cDNA coding for NET (HEK-NET) to investigate the affinity of NET for MIBG. The expression of recombinantly expressed SERT and NET was demonstrated by Western blotting analysis using primary antibodies against SERT (Fig. 2a) and NET (Fig. 2b). HEK-SERT cells rapidly accumulated $\left[{ }^{3} \mathrm{H}\right]$ serotonin (Fig. 2c). In contrast, no uptake of serotonin was observed for HEK293 cells transfected with the empty vector alone (HEK-Mock). Uptake assays using various substrate concentrations of $\left[{ }^{3} \mathrm{H}\right]$ serotonin 
a

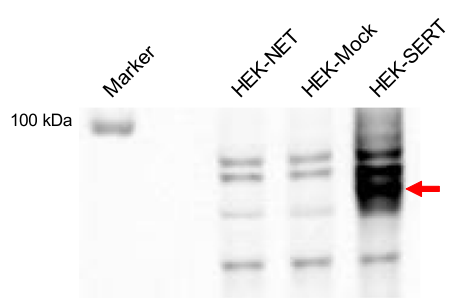

c

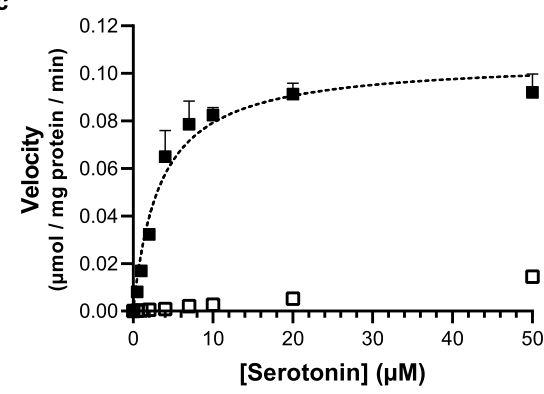

e

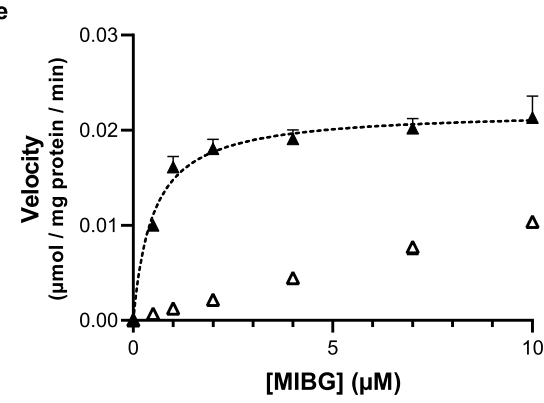

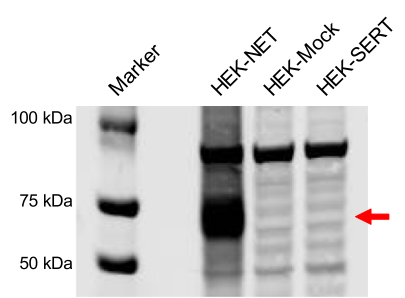

d

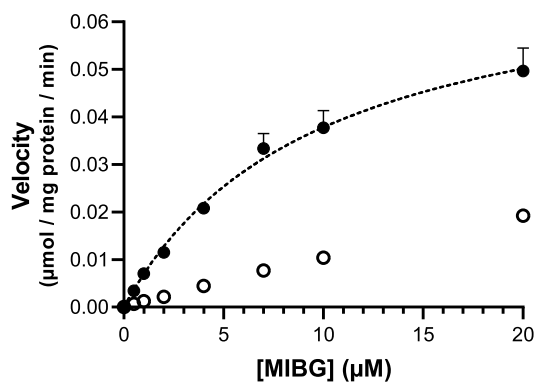

f

\begin{tabular}{l|r|r|r|}
$\begin{array}{r}\text { Celline } \\
\text { Substrate }\end{array}$ & HEK-SERT & HEK-SERT \\
Serotonin & MIBG & $\begin{array}{r}\text { HEK-NET } \\
\text { MIBG }\end{array}$ \\
\hline $\mathbf{V}_{\max }$ & 0.11 & 0.074 & 0.022 \\
$\mathbf{K}_{\mathbf{m}}$ & 3.6 & 9.7 & 0.49 \\
Catalytic eff. & 0.032 & 0.0077 & 0.045
\end{tabular}

Fig. 2 Uptake of $\left[{ }^{3} \mathrm{H}\right]$ serotonin and ${ }^{125}$ I]MIBG in SERT- and NET-transfected HEK293 cells. $\mathbf{a}$, b Results of Western blotting analysis on samples of transfected HEK cells. a Primary antibody against human SERT. b Primary antibody against human NET. c Uptake of $\left[{ }^{3} \mathrm{H}\right]$ serotonin by HEK-SERT cells. $\mathbf{d}$ Uptake of $\left[{ }^{125}\right.$ I]MIBG by HEK-SERT cells. e Uptake of [ ${ }^{125}$ ] MIBGG by HEK-NET cells. Closed symbols $(\mathbf{\bullet}, \bullet, \mathbf{\Delta})$ represent baseline-corrected, transporter-specific uptake. Open symbols $(\square, 0, \Delta)$ represent non-specific cellular uptake observed in HEK-Mock cells. Cells were incubated with substrate for $1 \mathrm{~h}$. The Michaelis-Menten graph is depicted as a black dashed line. $\mathbf{f}$ The kinetic parameters from this analysis: $V_{\max }$ in $\mu \mathrm{mol} / \mathrm{mg}$ protein/min; $K_{m}$ in $\mu \mathrm{M}$; catalytic efficiency: ratio $\frac{V_{\max }}{K_{m}}$. Data represent mean $\pm \operatorname{SD}(n=2)$

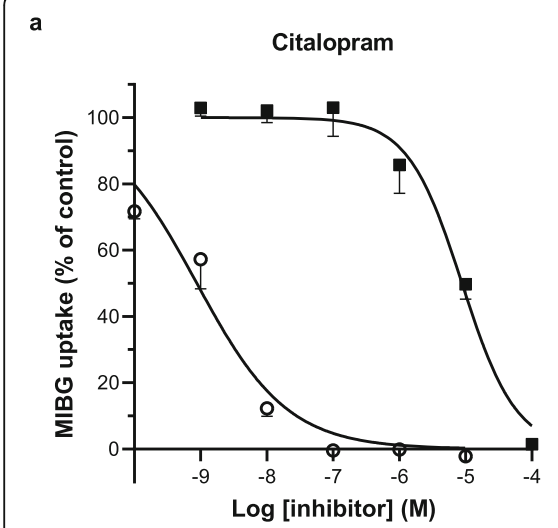

b

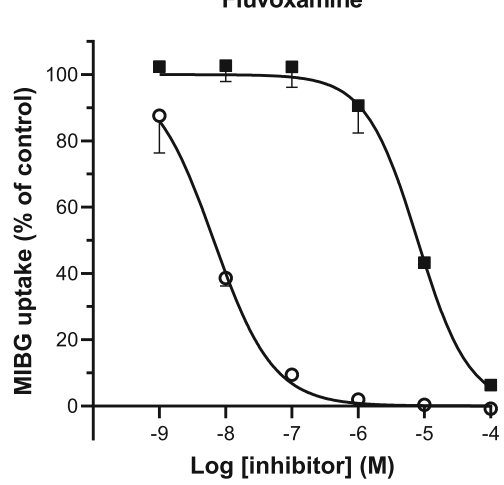

C

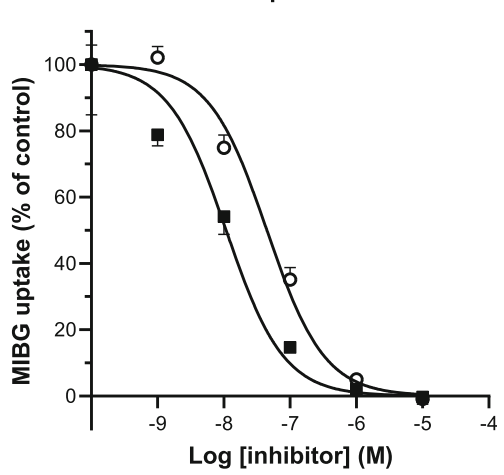

Fig. 3 Inhibition of [125]]MIBG uptake in SERT- and NET-transfected HEK293 cells by SSRIs and desipramine. MIBG uptake assays were performed on HEK-SERT cells (open symbols o) or HEK-NET cells (closed symbols $\mathbf{a}$ ) in the presence of various concentrations of citalopram (a), fluvoxamine (b), and desipramine (c). $\left.{ }^{125} \mid\right]$ MIBG uptake is expressed relative to assays conducted in the absence of inhibitors. Cells were incubated for $1 \mathrm{~h}$ with a substrate concentration of $10^{-6} \mathrm{M}$. Data represent mean $\pm \mathrm{SD}(n=2)$ 
confirmed saturability of substrate transport, with a highaffinity interaction $\left(K_{\mathrm{m}}=3.6 \mu \mathrm{M}\right)$. For the substrate $\left[{ }^{125} \mathrm{I}\right] \mathrm{MIBG}$, SERT performed as a low-affinity transporter $\left(K_{\mathrm{m}}=9.7 \mu \mathrm{M}\right.$; Fig. $\left.2 \mathrm{~d}\right)$ in comparison with NET (HEKNET, $K_{\mathrm{m}}=0.49 \mu \mathrm{M}$, Fig. 2e). The nonspecific uptake of serotonin represented only 3\% of total uptake in SERTtransfected cells, whereas it accounted for $22 \%$ and $33 \%$ of MIBG uptake in SERT and NET transfected cells, respectively, at a substrate concentration of $10^{-5} \mathrm{M}$.

To investigate the inhibitory potency of monoamine transporter inhibitors on the $\left[{ }^{125} \mathrm{I}\right] \mathrm{MIBG}$ uptake by SERT and NET, the effect of the SSRIs citalopram and fluvoxamine was compared to the tricyclic antidepressant desipramine, an inhibitor with a selectivity for NET (see also Fig. 1). Citalopram (Fig. 3a) and fluvoxamine (Fig. 3b) both potently inhibited the uptake of $\left[{ }^{125} \mathrm{I}\right]$ MIBG in HEK-SERT cells with no significant inhibitory effect at low concentrations on HEK-NET cells. Desipramine inhibited the uptake of $\left[{ }^{125} \mathrm{I}\right] \mathrm{MIBG}$ in both HEK-NET and HEK-SERT cells, with a stronger inhibitory effect in HEK-NET (Fig. 3c).

\section{In vitro selectivity of SSRIs in platelets and neuroblastoma cells}

Next, we tested whether the SSRIs can effectively block the uptake of $\left[{ }^{3} \mathrm{H}\right]$ serotonin and $\left[{ }^{125} \mathrm{I}\right] \mathrm{MIBG}$ in human platelets. Co-incubation with the SSRIs citalopram, fluvoxamine, fluoxetine, and sertraline showed effective, inhibitor concentration-dependent inhibition of the uptake of both substrates (Fig. 4). The degree of inhibition by these SSRIs was very similar for both serotonin and MIBG, indicating that both substrates are taken up by the same transporter (SERT). The total uptake (percentage of added radioactivity) in the control samples without SSRIs amounted to $57.5 \pm 13.8 \%$ for serotonin $(n=$ 5) and $23.6 \pm 3.6 \%$ for MIBG $(n=17)$. Nonspecific uptake (percentage of controls) was $2.6 \pm 0.4 \%$ for serotonin and $12.3 \pm 2.5 \%$ for MIBG.
In the subsequent experiments, the effect of different monoamine transporter inhibitors on the $\left[{ }^{125} \mathrm{I}\right] \mathrm{MIBG}$ uptake was compared between human platelets (uptake via SERT) and human SK-N-SH neuroblastoma cells (uptake via NET). The tested SSRIs (Fig. 5a) were more potent in inhibiting the MIBG uptake in platelets than in SK-N-SH cells. For example, citalopram at a concentration of $10^{-7} \mathrm{M}$ nearly fully inhibited the uptake of MIBG in platelets with negligible effect on the MIBG uptake in SK-N-SH neuroblastoma cells. To compare the effects of the SSRIs with monoamine transporter inhibitors from the tricyclic antidepressant family, we included clomipramine, imipramine, and desipramine in our analysis (Fig. 5b). Imipramine and desipramine, while able to inhibit the MIBG uptake in platelets, also have a profound inhibitory effect on the uptake of MIBG in neuroblastoma cells. This difference in selectivity is in line with earlier described selectivity factors (i.e., clomipramine: more SERT selective; imipramine: NET $\approx$ SERT; desipramine: more NET selective; see also Fig. 1) [24].

The potency and selectivity of all SSRIs tested in comparison with the tricyclic antidepressants and maprotiline, an inhibitor with high selectivity for NET, are listed in Table 1 [4, 25]. The most potent inhibitor of the $\left[{ }^{125} \mathrm{I}\right] \mathrm{MIBG}$ uptake in platelets was paroxetine with an $\mathrm{IC}_{50}$ of $0.2 \mathrm{nM}$. We defined the selectivity factor as the $\mathrm{IC}_{50}$ ratio of the MIBG uptake in platelets over that in SK-N-SH cells. Of the seven tested SSRIs, citalopram proved to be the most selective MIBG inhibitor, being approximately 1500 times more potent in inhibiting the MIBG uptake in platelets than in SK-N-SH neuroblastoma cells. Comparable results were obtained with platelets from healthy volunteers (data not shown).

MIBG uptake and inhibition studies with PC12 pheochromocytoma cells were included to investigate the role of cytoplasmic storage granules. The $\mathrm{IC}_{50}$ values of the monoamine transporter inhibitors for the inhibition of MIBG uptake in PC12 cells proved to be similar to those
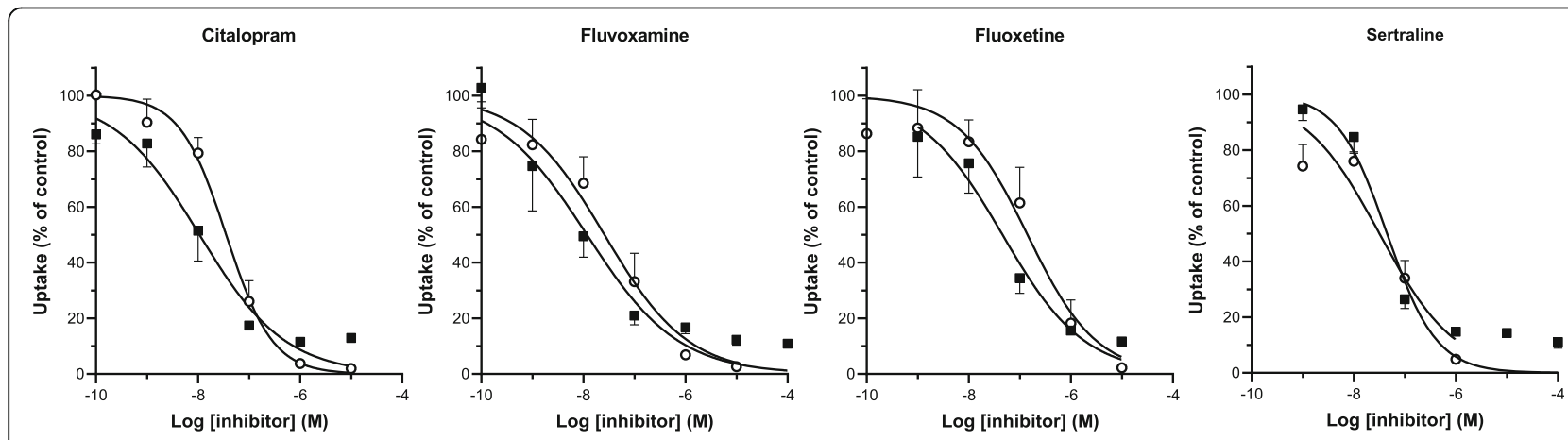

Fig. 4 Inhibition of $\left[{ }^{3} \mathrm{H}\right]$ serotonin and $\left[{ }^{125}\right.$ I]MIBG uptake by SSRIs in human platelets. Inhibition of $\left[{ }^{3} \mathrm{H}\right]$ serotonin uptake is depicted by open symbols (o), and inhibition of [ ${ }^{125}$ I]MIBG uptake by closed symbols (-). Samples were incubated at $37^{\circ} \mathrm{C}$ for 15 min (serotonin) or 4 h (MIBG) with a substrate concentration of $10^{-8} \mathrm{M}$. Substrate uptake is expressed as the percentage of control without inhibitor. Data represent mean $\pm \mathrm{SD}(n=4-7)$ 


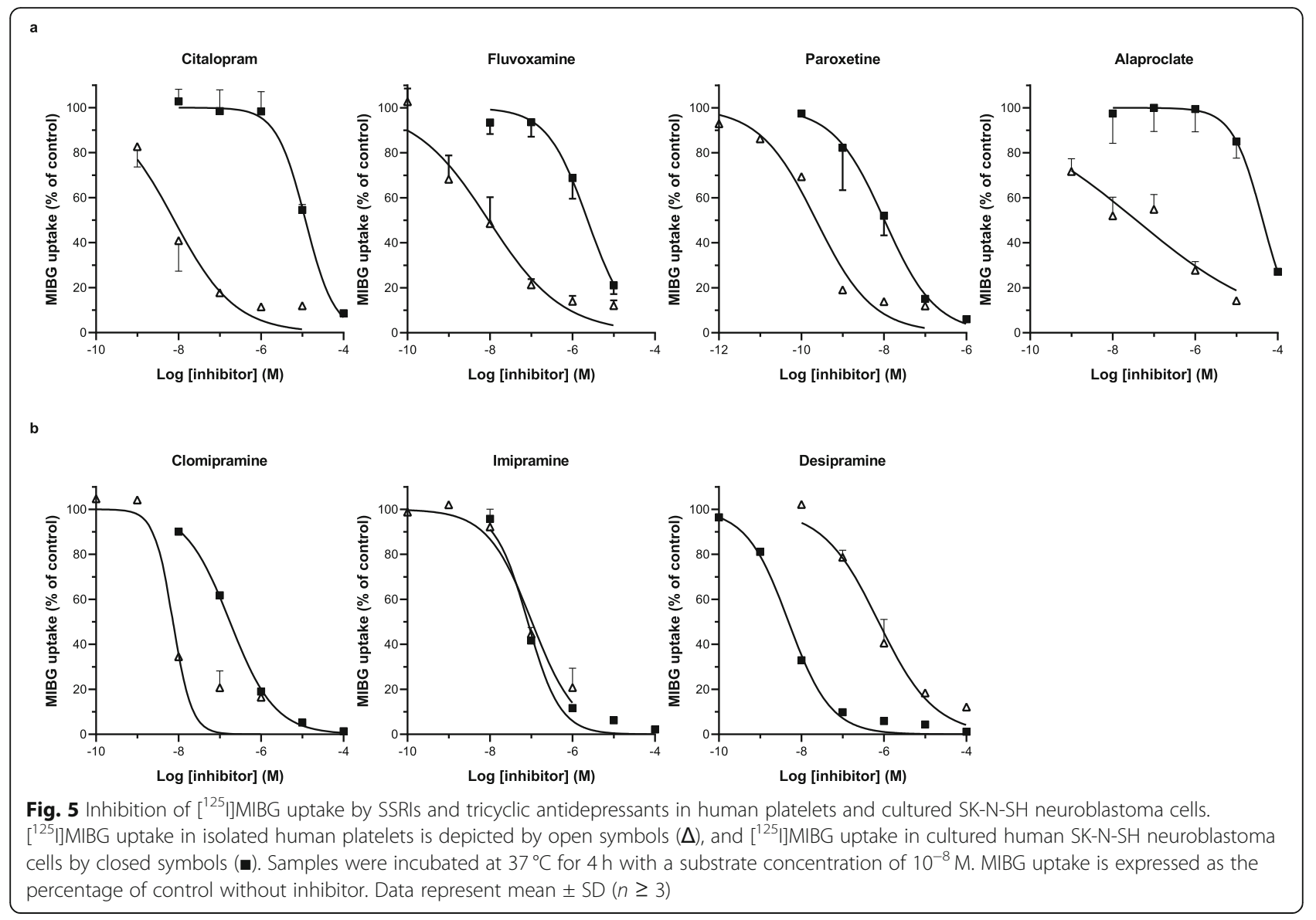

Table 1 The potency and selectivity of all tested monoamine transporter inhibitors

\begin{tabular}{|c|c|c|c|c|c|}
\hline & & \multicolumn{3}{|c|}{$\mathrm{IC}_{50}(\mathrm{nM})$ of uptake inhibition } & \multirow{3}{*}{$\begin{array}{l}\text { Selectivity factor } \\
\mathrm{IC}_{\mathbf{5 0}} \text { ratio }\end{array}$} \\
\hline & & \multicolumn{2}{|l|}{ Platelets } & \multirow{2}{*}{$\begin{array}{l}\text { SK-N-SH } \\
{\left[{ }^{125} \mid\right] M I B G}\end{array}$} & \\
\hline & & {$\left[{ }^{3} \mathrm{H}\right]$ Serotonin } & {$\left[{ }^{125} \mid\right] \mathrm{MIBG}$} & & \\
\hline \multirow[t]{7}{*}{ SSRIS } & Alaproclate & 516 & 38 & 43420 & 1158 \\
\hline & Citalopram & 32 & 7.8 & 11940 & 1521 \\
\hline & Fluvoxamine & 30 & 9.3 & 2339 & 252 \\
\hline & Fluoxetine & 115 & 32 & 1270 & 40 \\
\hline & Norfluoxetine & 107 & 24 & 2760 & 115 \\
\hline & Paroxetine & 0.6 & 0.2 & 10 & 45 \\
\hline & Sertraline & 41 & 36 & 3301 & 91 \\
\hline \multirow[t]{3}{*}{ TCAs } & Clomipramine & 18 & 7 & 176 & 24 \\
\hline & Imipramine & 118 & 104 & 82 & 0.8 \\
\hline & Desipramine & 648 & 744 & 5 & 0.007 \\
\hline TeCA & Maprotiline & n.d. & $1000-10,000$ & 39 & $0.04-0.004$ \\
\hline
\end{tabular}

Selective inhibition of $10^{-8} \mathrm{M}\left[{ }^{125}\right.$ I]MIBG or $\left[{ }^{3} \mathrm{H}\right]$ serotonin uptake by monoamine transporter inhibitors in human platelets or SK-N-SH neuroblastoma cells in vitro. Selectivity was expressed as the $\mathrm{IC}_{50}$ ratio of the MIBG uptake in SK-N-SH cells over that in platelets. SSRI Selective serotonin reuptake inhibitor; TCA Tricyclic antidepressant; TeCA Tetracyclic antidepressant 
observed in the assays with the SK-N-SH neuroblastoma cells (data not shown), indicating that the MIBG uptake inhibitors only interfered with transport across the outer cell membrane and not with granular accumulation.

\section{Effect of monoamine transporter inhibitors on the $\left[{ }^{125}\right.$ I]MIBG tumor uptake in vivo}

Next, we studied in an in vivo model of SK-N-SH neuroblastoma-xenografted mice whether plasma drug levels, that prevent platelet MIBG uptake, could be realized without affecting radioiodinated MIBG tumor uptake. The administered doses of desipramine $(20 \mathrm{mg} / \mathrm{kg})$ and the four in vitro most potent SSRIs citalopram (20 $\mathrm{mg} / \mathrm{kg})$, fluvoxamine $(50 \mathrm{mg} / \mathrm{kg})$, sertraline $(20 \mathrm{mg} / \mathrm{kg})$, and paroxetine $(2 \mathrm{mg} / \mathrm{kg})$ were well tolerated, as neither detectable motor nor behavioral abnormalities were observed. The $\left.{ }^{125} \mathrm{I}\right] \mathrm{MIBG}$ accumulation in the neuroblastoma xenografts (Fig. 6) was not significantly affected by treatment with any of the four SSRIs, but was diminished by $60 \%$ in mice treated with desipramine, as expected from our in vitro studies with desipramine and SK-N-SH cells.
Similar in vivo studies with mice bearing PC12 pheochromocytoma xenografts resulted in no significant difference in tumor MIBG uptake after treatment with citalopram and sertraline (data not shown). In contrast to our results obtained with neuroblastoma xenografts, fluvoxamine reduced the pheochromocytoma-associated radioactivity with $64 \%(p<0.002)$. Paroxetine was not tested. Desipramine treatment of mice bearing PC12 pheochromocytoma xenografts resulted in the same reduction of MIBG uptake as seen in SK-N-SH neuroblastoma xenografts $(p<0.004)$.

Regarding normal tissues (Fig. 6), SSRI treatments had no significant effect on the $\left[{ }^{125}\right.$ I]MIBG levels in the blood, intestines, ears/skin, kidneys, brains (data not shown), spleen, and adrenals. For the liver, MIBG levels after SSRI treatment were highly variable and contradictory. The $\left[{ }^{125} \mathrm{I}\right]$ MIBG concentration in the livers of mice undergoing fluvoxamine or sertraline treatment was not significantly different from controls. Citalopram treatment, however, led to a 35\% decrease in MIBG levels, whereas paroxetine resulted in a $17 \%$ increase. In addition, we observed consistent higher (14-25\%)

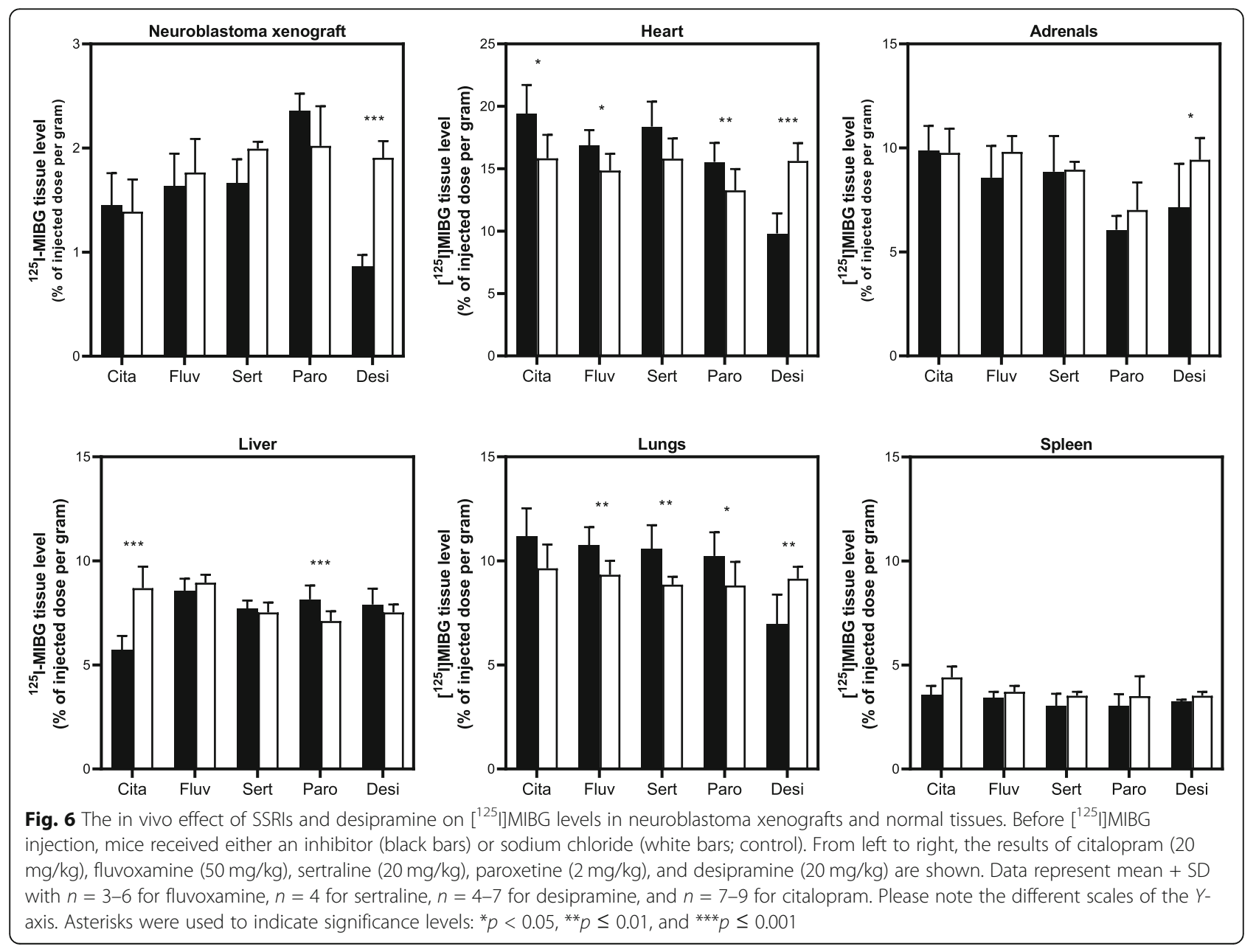


$\left[{ }^{125}\right.$ I]MIBG levels in the heart and lungs in the SSRItreated mice. Desipramine significantly reduced the $\left[{ }^{125} \mathrm{I}\right] \mathrm{MIBG}$ uptake of the heart, lungs, and adrenals with $24-37 \%$, but this reduction was less pronounced than in neuroblastoma xenografts, as described above.

\section{Ex vivo bioassay of murine plasma SSRI activity}

To assess the inhibitory potency of plasma of mice treated with the different SSRIs as described above, this plasma was added to human platelets to measure the inhibition of $\left[{ }^{125} \mathrm{I}\right] \mathrm{MIBG}$ uptake in platelets. The results depicted in Fig. 7 demonstrate that the SSRI drug levels in the murine circulation highly exceeded those required for effective inhibition of $\left[{ }^{125}\right.$ I]MIBG uptake in human platelets.

\section{Discussion}

The most common side effect encountered after $\left[{ }^{131}\right.$ I]MIBG therapy is hematological toxicity, in particular thrombocytopenia. Since platelets are anucleate cells with a finite lifespan, and the observed thrombocytopenia is not an instantaneous toxicity, it is conceivable that platelet precursor cells, i.e., megakaryocytes located in the bone marrow, are the primary targets of radiotoxic MIBG. The uptake of MIBG by HEK-SERT cells and in platelets as observed in our study is in line with a previous study [18], demonstrating the promiscuity of MIBG for two related but different monoamine transporters, namely SERT and NET. Moreover, we showed that SSRIs were effective in reducing the MIBG uptake in human platelets. Since both platelets and their precursor cells, megakaryocytes, express the serotonin transporter on their cell membrane [26, 27], the application of SSRIs could be used to circumvent $\left[{ }^{131} \mathrm{I}\right]$ MIBG-induced thrombocytopenia.
We have, therefore, investigated whether inhibition of MIBG accumulation in platelets by SSRIs is feasible without affecting MIBG tumor uptake in neuroblastoma, using in vitro and in vivo models. Our finding that paroxetine is both the most potent serotonin and MIBG inhibiting SSRI is consistent with previous investigations $[24,25,28-31]$. That potency and selectivity do not coincide can be appreciated by comparing paroxetine and citalopram. In our in vitro MIBG uptake assays, the most selective drug proved to be citalopram, being 1500 -fold more potent in preventing uptake of MIBG in platelets than in SK-N-SH neuroblastoma cells. These results are consistent with previous studies, which showed that citalopram is the most selective SSRI, being a far more potent inhibitor of SERT than of NET [24, 25, 32, 33].

In our in vivo model of mice bearing a human neuroblastoma xenograft, none of the tested SSRIs significantly affected MIBG accumulation in the tumor. Intervention with any of the four tested SSRIs led to a slight increase of MIBG levels in the heart and lungs. It is known that the instant effect of short-term SSRI treatment is suppression of sympathetic nervous system activity [34, 35]. Presumably, this suppression results in more "leftover capacity" for NET to transport MIBG intracellular in the sympathetic end organs. In contrast, a recent in vivo rabbit study found no impact of the SSRI escitalopram on cardiac [ $\left.{ }^{123} \mathrm{I}\right] \mathrm{MIBG}$ uptake [36]. In the liver, citalopram and paroxetine had diametrically opposed effects on the MIBG accumulation. The serotonin transporter, localized on hepatocytes and on hepatic stellate cells, plays an important, although not completely understood, role in hepatic repair after injury $[37,38]$. One would expect, therefore, that administration of a SSRI would be accompanied by a decrease in

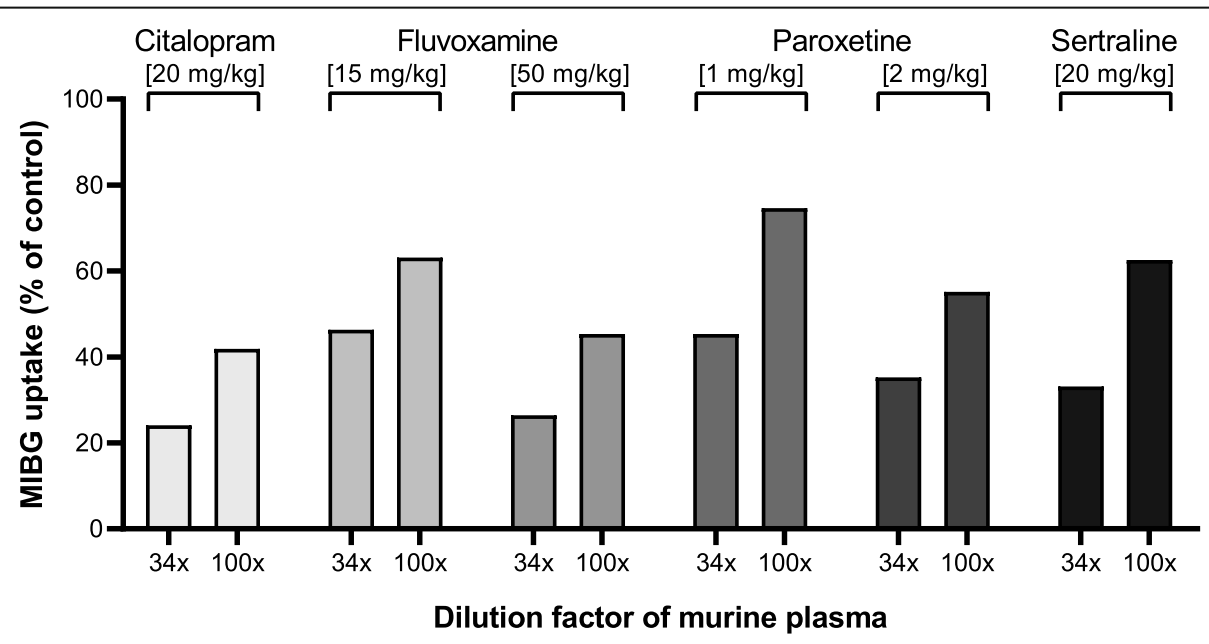

Fig. 7 Inhibition of $\left[{ }^{125}\right]$ MIBG uptake in isolated human platelets by different dilutions of murine plasma obtained from SSRI-treated mice. One hour before collecting plasma, mice intraperitoneally received the monoamine transporter inhibitor at the dose indicated in parenthesis. Data are from a representative experiment performed in duplicate and were confirmed by at least 2 experiments performed at slightly different conditions 
hepatic MIBG uptake, such as we encountered with citalopram. Administration of paroxetine, however, led to a small increase in hepatic MIBG uptake. At this moment, the underlying mechanism that could account for the observed results remains to be elucidated.

The intended purpose of a pharmacological intervention with a SSRI would be to prevent thrombocytopenia due to $\left[{ }^{131} \mathrm{I}\right]$ MIBG uptake after the infusion of a therapeutic dose of radiotoxic MIBG. To accomplish this, our desired SSRI should be effective for a discrete period of time after a single ingestion. The primary metabolite of citalopram, desmethylcitalopram, is only slightly less potent and selective than citalopram in inhibiting SERT in vitro $[24,39]$. After oral ingestion, citalopram is completely absorbed: maximum plasma drug levels are reached within $4 \mathrm{~h}$, and plasma half-life of $33-54 \mathrm{~h}$ is appropriate for the objective stated above [40, 41]. Fluvoxamine also has favorable pharmacokinetic properties [42]. However, a case report of an 11-year-old boy whose ingestion of a single dose of fluvoxamine resulted in serotonin syndrome [43] led us to conclude that citalopram seems the most suitable candidate to protect the platelets and precursor megakaryocytes from intracellular radiation in patients undergoing MIBG therapy. Citalopram has some additional advantages over the other SSRIs. For instance, fluoxetine (1-4 days) and its primary and active metabolite, norfluoxetine (7-15 days), have very long elimination half-lives [44]. Sertraline is not applicable for single-dose administration because only $44 \%$ is absorbed after oral ingestion [45]. Paroxetine undergoes extensive first-pass metabolism, reducing its bioavailability to approximately $50 \%$ [46].

Citalopram is capable of fully and selectively reducing MIBG uptake in platelets, without interfering with MIBG tumor uptake. Moreover, plasma concentrations of citalopram that will inhibit SERT [47] had no effect on platelet function [48], making it highly unlikely that a single ingestion of citalopram will have an effect on hemostasis and thrombosis [49]. Combined with the above-described favorable pharmacokinetic properties, we recommend citalopram for further preclinical and clinical studies on the prevention of MIBG accumulation in megakaryocytes. Previous studies failed to demonstrate MIBG uptake in megakaryocytic cell lines [50] and in human megakaryocytes [51], probably due to suboptimal in vitro culture conditions. A case report of osteomedullary MIBG uptake in a 13-month-old patient with acute megakaryocytic leukemia argues, however, in favor of the capacity of cells from the megakaryocytic lineage to concentrate MIBG [52]. Recently, SERT expression in human megakaryoblastic MEG-01 cells has been demonstrated unequivocally by different research groups [26, 27]. In ongoing studies, with optimized experimental conditions, we will investigate the inhibitory potential of SSRIs on the MIBG accumulation in megakaryocytes, bone marrow supporting stroma cells, and other hematopoietic cells, to further elucidate the underlying mechanisms of MIBG-related toxicity.

\section{Conclusions}

Selective serotonin reuptake inhibitors (SSRIs) are able to prevent MIBG uptake in platelets without affecting neuroblastoma tumor uptake in an in vivo mouse model. The concomitant application of a SSRI during $\left[{ }^{131} \mathrm{I}\right]$ MIBG therapy appears to be a promising strategy to prevent thrombocytopenia in neuroblastoma patients. Future studies will investigate the inhibitory potential of SSRIs on the MIBG accumulation in the parent cells responsible for the production of platelets, human megakaryocytes.

\section{Supplementary information}

Supplementary information accompanies this paper at https://doi.org/10. 1186/s13550-020-00662-w.

Additional file 1: Supplementary Table I. A summary of reuptake inhibitor studies in rodents using behavioral or biochemical analysis to determine the effective dose

\section{Abbreviations}

SSRI: Selective serotonin reuptake inhibitor; MIBG: Meta-iodobenzylguanidine; NET: Norepinephrine transporter; SERT: Serotonin transporter; $\mathrm{IC}_{50}$ : Half maximal inhibitory concentration; ATCC: American Type Culture Collection; PRP: Platelet-rich plasma; HBSS: Hank's Balanced Salt Solution; S.c.: Subcutaneous; IP: Intraperitoneal; HEK: Human embryonic kidney

\section{Acknowledgements}

Not applicable

\section{Authors' contributions}

TB, MR, MD, AvK, GT conceived and designed the analysis. TB, RM, CB, MD GT collected the data. TB, RM, CB, MD, GT contributed data or analysis tools. TB, MR, AvK, GT performed the analysis. TB, MR, AvK, GT wrote the paper. The author(s) read and approved the final manuscript.

\section{Funding}

This study was funded by the Foundation for Pediatric Cancer Research (grant number 93-0110, the Dutch Cancer Society (grant number NKI-94-804) and the European Community (grant number BMH4-CT98-3297).

\section{Availability of data and materials}

The datasets generated during and/or analyzed during the current study are available from the corresponding author on reasonable request.

\section{Ethics approval and consent to participate}

This study was approved by the Medical Ethical Committee of the Amsterdam University Medical Center.

Informed consent was obtained from patients whom platelet-rich plasma was used in this study.

Mice were bred in the animal facility of the Netherlands Cancer Institute. Experiments were performed in accordance with the national regulations for animal experimentations, and protocols were approved by the local animal welfare committee. All applicable international, national, and/or institutional guidelines for the care and use of animals were followed.

Consent for publication

Not applicable

Competing interests

All authors declare that they have no conflict of interest. 


\section{Author details}

${ }^{1}$ Princess Máxima Center for Pediatric Oncology, Utrecht, The Netherlands. ${ }^{2}$ Gastroenterology \& Metabolism, Department of Clinical Chemistry, Amsterdam University Medical Center, Amsterdam, The Netherlands. ${ }^{3}$ Department of Experimental Therapy, Netherlands Cancer Institute, Amsterdam, The Netherlands. ${ }^{4}$ Department of Pediatric Oncology, Emma Children's Hospital, Amsterdam University Medical Center, Amsterdam, The Netherlands.

Received: 2 January 2020 Accepted: 25 June 2020

Published online: 08 July 2020

\section{References}

1. Matthay KK, Maris JM, Schleiermacher G, Nakagawara A, Mackall CL, Diller L, et al. Neuroblastoma. Nature reviews Disease primers. 2016;2:16078. https:// doi.org/10.1038/nrdp.2016.78.

2. Maris JM. Recent advances in neuroblastoma. N Engl J Med. 2010;362(23): 2202-11. https://doi.org/10.1056/NEJMra0804577.

3. Streby KA, Shah N, Ranalli MA, Kunkler A, Cripe TP. Nothing but NET: a review of norepinephrine transporter expression and efficacy of 1311-mIBG therapy. Pediatric blood \& cancer. 2015;62(1):5-11. https://doi.org/10.1002/ pbc.25200.

4. Maitre L, Moser P, Baumann PA, Waldmeier PC. Amine uptake inhibitors: criteria of selectivity. Acta Psychiatr Scand. 1980;61(\$280):97-110. https://doi. org/10.1111/acps.1980.61.s280.97.

5. Vik TA, Pfluger T, Kadota R, Castel V, Tulchinsky M, Farto JC, et al. (123)lmIBG scintigraphy in patients with known or suspected neuroblastoma: results from a prospective multicenter trial. Pediatr Blood Cancer. 2009;52(7): 784-90. https://doi.org/10.1002/pbc.21932.

6. Treuner J, Klingebiel T, Bruchelt G, Feine U, Niethammer D. Treatment of neuroblastoma with metaiodobenzylguanidine: results and side effects. Medical and pediatric oncology. 1987;15(4):199-202.

7. Voute PA, Hoefnagel CA, de Kraker J, Majoor M. Side effects of treatment with I-131-meta-iodobenzylguanidine (I-131-MIBG) in neuroblastoma patients. Prog Clin Biol Res. 1988;271:679-87.

8. Matthay KK, DeSantes K, Hasegawa B, Huberty J, Hattner RS, Ablin A, et al. Phase I dose escalation of 131I-metaiodobenzylguanidine with autologous bone marrow support in refractory neuroblastoma. J Clin Oncol. 1998;16(1): 229-36. https://doi.org/10.1200/JCO.1998.16.1.229.

9. DuBois SG, Messina J, Maris JM, Huberty J, Glidden DV, Veatch J, et al. Hematologic toxicity of high-dose iodine-131-metaiodobenzylguanidine therapy for advanced neuroblastoma. J Clin Oncol. 2004;22(12):2452-60. https://doi.org/10.1200/jco.2004.08.058.

10. Matthay KK, Panina C, Huberty J, Price D, Glidden DV, Tang HR, et al. Correlation of tumor and whole-body dosimetry with tumor response and toxicity in refractory neuroblastoma treated with (131)I-MIBG. J Nucl Med. 2001;42(11):1713-21.

11. Trieu M, DuBois SG, Pon E, Nardo L, Hawkins RA, Marachelian A, et al. Impact of whole-body radiation dose on response and toxicity in patients with neuroblastoma after therapy with 131 I-metaiodobenzylguanidine (MIBG). Pediatr Blood Cancer. 2016;63(3):436-42. https://doi.org/10.1002/pbc. 25816.

12. Rutgers $M$, Buitenhuis CK, van der Valk MA, Hoefnagel CA, Voute PA, Smets LA. [(131)I] and [(125)I] metaiodobenzylguanidine therapy in macroscopic and microscopic tumors: a comparative study in SK-N-SH human neuroblastoma and PC12 rat pheochromocytoma xenografts. Int I Cancer. 2000;90(6):312-25.

13. Sisson JC, Hutchinson RJ, Shapiro B, Zasadny KR, Normolle D, Wieland DM, et al. lodine-125-MIBG to treat neuroblastoma: preliminary report. J Nucl Med. 1990;31(9):1479-85.

14. Sisson JC, Shapiro B, Hutchinson RJ, Carey JE, Zasadny KR, Zempel SA, et al. Predictors of toxicity in treating patients with neuroblastoma by radiolabeled metaiodobenzylguanidine. Eur J Nucl Med. 1994;21(1):46-52.

15. Welt S, Divgi CR, Kemeny N, Finn RD, Scott AM, Graham M, et al. Phase I/II study of iodine 131-labeled monoclonal antibody A33 in patients with advanced colon cancer. J Clin Oncol. 1994;12(8):1561-71. https://doi.org/10. 1200/jco.1994.12.8.1561.

16. Welt S, Scott AM, Divgi CR, Kemeny NE, Finn RD, Daghighian F, et al. Phase I/II study of iodine 125-labeled monoclonal antibody A33 in patients with advanced colon cancer. J Clin Oncol. 1996;14(6):1787-97. https://doi.org/10. 1200/JCO.1996.14.6.1787.
17. Jedlitschky G, Greinacher A, Kroemer HK. Transporters in human platelets: physiologic function and impact for pharmacotherapy. Blood. 2012;119(15): 3394-402. https://doi.org/10.1182/blood-2011-09-336933.

18. Rutgers M, Tytgat GA, Verwijs-Janssen M, Buitenhuis C, Voute PA, Smets LA. Uptake of the neuron-blocking agent meta-iodobenzylguanidine and serotonin by human platelets and neuro-adrenergic tumour cells. Int J Cancer. 1993;54(2):290-5.

19. Rutgers M, Buitenhuis CK, Hoefnagel CA, Voute PA, Smets LA. Targeting of meta-iodobenzylguanidine to SK-N-SH human neuroblastoma xenografts: tissue distribution, metabolism and therapeutic efficacy. Int J Cancer. 2000; 87(3):412-22.

20. Smets $L A$, Janssen $M$, Rutgers $M$, Ritzen $K$, Buitenhuis $C$. Pharmacokinetics and intracellular distribution of the tumor-targeted radiopharmaceutical miodo-benzylguanidine in SK-N-SH neuroblastoma and PC-12 pheochromocytoma cells. Int J Cancer. 1991;48(4):609-15.

21. Gaze MN, Hamilton TG, Mairs RJ. Pharmacokinetics and efficacy of 1311meta-iodobenzylguanidine in two neuroblastoma xenografts. Br J Radiol. 1994;67(798):573-8. https://doi.org/10.1259/0007-1285-67-798-573.

22. Bjerkenstedt $L$, Flyckt L, Overo KF, Lingjaerde O. Relationship between clinical effects, serum drug concentration and serotonin uptake inhibition in depressed patients treated with citalopram. A double-blind comparison of three dose levels. Eur J Clin Pharmacol. 1985;28(5):553-7.

23. Fuller RW, Wong DT. Serotonin uptake and serotonin uptake inhibition. Ann N Y Acad Sci. 1990;600:68-78; discussion 9-80.

24. Tatsumi M, Groshan K, Blakely RD, Richelson E. Pharmacological profile of antidepressants and related compounds at human monoamine transporters. Eur J Pharmacol. 1997;340(2-3):249-58.

25. Hyttel J. Pharmacological characterization of selective serotonin reuptake inhibitors (SSRIs). Int Clin Psychopharmacol. 1994;9(Suppl 1):19-26.

26. Giannaccini G, Betti L, Palego L, Schmid L, Fabbrini L, Pelosini C, et al. Human serotonin transporter expression during megakaryocytic differentiation of MEG-01 cells. Neurochem Res. 2010;35(4):628-35. https:// doi.org/10.1007/s11064-009-0112-8.

27. Hohmann S, Schweinfurth N, Lau T, Deuschle M, Lederbogen F, Banaschewski T, et al. Differential expression of neuronal dopamine and serotonin transporters DAT and SERT in megakaryocytes and platelets generated from human MEG-01 megakaryoblasts. Cell Tissue Res. 2011; 346(2):151-61. https://doi.org/10.1007/s00441-011-1256-9.

28. Mellerup ET, Plenge $\mathrm{P}$, Engelstoft $\mathrm{M}$. High affinity binding of $[3 \mathrm{H}]$ paroxetine and [3H]imipramine to human platelet membranes. Eur J Pharmacol. 1983; 96(3-4):303-9. https://doi.org/10.1016/0014-2999(83)90321-7.

29. Hoffman BJ, Mezey E, Brownstein MJ. Cloning of a serotonin transporter affected by antidepressants. Science. 1991;254(5031):579-80. https://doi.org/ 10.1126/science.1948036.

30. Ramamoorthy S, Bauman AL, Moore KR, Han H, Yang-Feng T, Chang AS, et al. Antidepressant- and cocaine-sensitive human serotonin transporter: molecular cloning, expression, and chromosomal localization. Proc Natl Acad Sci U S A. 1993;90(6):2542-6.

31. Alexander SP, Kelly E, Marrion NV, Peters JA, Faccenda E, Harding SD, et al. The concise guide to pharmacology 2017/18: transporters. Br J Pharmacol. 2017;174(Suppl 1):S360-s446. https://doi.org/10.1111/bph.13883.

32. Richelson E, Pfenning M. Blockade by antidepressants and related compounds of biogenic amine uptake into rat brain synaptosomes: most antidepressants selectively block norepinephrine uptake. Eur J Pharmacol. 1984;104(3-4):277-86. https://doi.org/10.1016/0014-2999(84)90403-5.

33. Mantovani M, Dooley DJ, Weyerbrock A, Jackisch R, Feuerstein TJ. Differential inhibitory effects of drugs acting at the noradrenaline and 5hydroxytryptamine transporters in rat and human neocortical synaptosomes. Br J Pharmacol. 2009;158(7):1848-56. https://doi.org/10.1111/ j.1476-5381.2009.00478.x

34. Shores MM, Pascualy M, Lewis NL, Flatness D, Veith RC. Short-term sertraline treatment suppresses sympathetic nervous system activity in healthy human subjects. Psychoneuroendocrinology. 2001;26(4):433-9.

35. Tiradentes RV, Pires JG, Silva NF, Ramage AG, Santuzzi CH, Futuro Neto HA. Effects of acute administration of selective serotonin reuptake inhibitors on sympathetic nerve activity. Braz J Med Biol Res. 2014;47(7):554-9. https://doi. org/10.1590/1414-431 x20143698.

36. Werner RA, Kobayashi R, Javadi MS, Kock Z, Wakabayashi H, Unterecker S, et al. Impact of novel antidepressants on cardiac (123)IMetaiodobenzylguanidine uptake: experimental studies on SK-N-SH cells 
and healthy rabbits. J Nucl Med. 2018;59(7):1099-103. https://doi.org/10. 2967/jnumed.117.206045

37. Ruddell RG, Oakley F, Hussain Z, Yeung I, Bryan-Lluka L, Ramm GA, et al. A role for serotonin (5-HT) in hepatic stellate cell function and liver fibrosis. Am J Pathol. 2006;169(3):861-76. https://doi.org/10.2353/ajpath.2006.050767.

38. Ruddell RG, Mann DA, Ramm GA. The function of serotonin within the liver. J Hepatol. 2008;48(4):666-75. https://doi.org/10.1016/j.jhep.2008.01.006.

39. Krout D, Rodriquez M, Brose SA, Golovko MY, Henry LK, Thompson BJ. Inhibition of the serotonin transporter is altered by metabolites of selective serotonin and norepinephrine reuptake inhibitors and represents a caution to acute or chronic treatment paradigms. ACS Chem Neurosci. 2017;8(5): 1011-8. https://doi.org/10.1021/acschemneuro.6b00343.

40. Gutierrez MM, Abramowitz W. Pharmacokinetic comparison of oral solution and tablet formulations of citalopram: a single-dose, randomized, crossover study. Clin Ther. 2000;22(12):1525-32.

41. Al-Ghazawi M, Tutunji M, Mohsen M, Najjar S. Pharmacokinetic comparison of two $40 \mathrm{mg}$ tablet formulations of citalopram using a new amperometric detection technique. Int J Clin Pharmacol Ther. 2007;45(5):300-6. https://doi. org/10.5414/cpp45300

42. Perucca E, Gatti G, Spina E. Clinical pharmacokinetics of fluvoxamine. Clin Pharmacokinet. 1994;27(3):175-90. https://doi.org/10.2165/00003088199427030-00002.

43. Gill M, LoVecchio F, Selden B. Serotonin syndrome in a child after a single dose of fluvoxamine. Ann Emerg Med. 1999:33(4):457-9.

44. Hiemke C, Hartter S. Pharmacokinetics of selective serotonin reuptake inhibitors. Pharmacol Ther. 2000;85(1):11-28.

45. van Harten J. Clinical pharmacokinetics of selective serotonin reuptake inhibitors. Clin Pharmacokinet. 1993;24(3):203-20. https://doi.org/10.2165/ 00003088-199324030-00003.

46. Holliday SM, Plosker GL. Paroxetine. A review of its pharmacology, therapeutic use in depression and therapeutic potential in diabetic neuropathy. Drugs Aging. 1993;3(3):278-99.

47. Milne RJ, Goa KL. Citalopram. A review of its pharmacodynamic and pharmacokinetic properties, and therapeutic potential in depressive illness. Drugs. 1991;41(3):450-77.

48. Roweth HG, Yan R, Bedwani NH, Chauhan A, Fowler N, Watson AH, et al. Citalopram inhibits platelet function independently of SERT-mediated 5-HT transport. Sci Rep. 2018;8(1):3494. https://doi.org/10.1038/s41598-018-21348-3.

49. Flock A, Zobel A, Bauriedel G, Tuleta I, Hammerstingl C, Hofels S, et al. Antiplatelet effects of antidepressant treatment: a randomized comparison between escitalopram and nortriptyline. Thromb Res. 2010;126(2):e83-7. https://doi.org/10.1016/j.thromres.2010.04.020.

50. Tytgat GA, Voute PA, Takeuchi S, Miyoshi I, Rutgers M. Metaiodobenzylguanidine uptake in platelets, megakaryoblastic leukaemia cell lines MKPL-1 and CHRF-28-11 and erythroleukaemic cell line HEL. Eur J Cancer. 1995;31a(4):603-6.

51. Tytgat GA, van den Brug MD, Voute PA, Smets LA, Rutgers M. Human megakaryocytes cultured in vitro accumulate serotonin but not metaiodobenzylguanidine whereas platelets concentrate both. Exp Hematol. 2002;30(6):555-63.

52. Leung A, Shapiro B, Brown M. I-131 localization in acute megakaryocytic leukemia. Clin Nucl Med. 1996;21(12):950-2.

\section{Publisher's Note}

Springer Nature remains neutral with regard to jurisdictional claims in published maps and institutional affiliations.

\section{Submit your manuscript to a SpringerOpen ${ }^{\circ}$ journal and benefit from:}

- Convenient online submission

- Rigorous peer review

- Open access: articles freely available online

- High visibility within the field

- Retaining the copyright to your article

Submit your next manuscript at $\boldsymbol{\nabla}$ springeropen.com 